\title{
LED RAILWAY SIGNAL VS FULL COMPLIANCE WITH COLORIMETRIC SPECIFICATIONS
}

\author{
G. SCHIRRIPA SPAGNOLO ${ }^{1}$, D. PAPALILLO ${ }^{1}$, C. MALTA $^{2} \&$ S. VINZANI ${ }^{2}$ \\ ${ }^{1}$ Department of Mathematics and Physics, University 'Roma Tre', Italy. \\ ${ }^{2}$ Rete Ferroviaria Italiana (RFI), Roma, Italy.
}

\begin{abstract}
In recent times, the transportation industry has generated a number of developments involving new technology in signalling. Important developments have involved the production of light by means of light-emitting diode (LED). Unfortunately, the maximum light output, dominant wavelength, reliability and the lifetime of LEDs are all closely related to the junction temperature. Accordingly, LED performance largely depends on the ambient temperature of its operating environment. Consequently, adequate heat-sinking is required to maintain a long lifetime and compliance. Today again, designing an LED railway signal that is able to meet compliance over wide range of temperatures is problematic. In particular, for yellow aspects compliance is difficult to achieve at extreme ambient temperature because the shift in the colour of yellow LEDs over the specified temperature range can be greater than the magnitude of colour specification. Use of phase change materials (PCMs) can provide practical solution of these problems. PCMs can store and release thermal energy during the process of melting and freezing (changing from one phase to another). When such a material freezes, it releases large amounts of energy in the form of latent heat of fusion or energy of crystallization. Conversely, when the material is melted, an equal amount of energy is absorbed from the environment as it changes from solid to liquid. This paper presents studies that enable the design of railway signals to meet, in a rigorous way, colorimetric compliances on a large range of temperature change. Furthermore, the proposed system is applicable, in a simple way and without operational changes, to the existing systems. It is sufficient to insert inside of the signals a suitable amount of a specific PCM.

Keywords: light-emitting diode (LED), phase change materials (PCM), railway signals.
\end{abstract}

\section{INTRODUCTION}

Light-emitting diodes (LEDs) are one of the fastest growing technologies in the lighting industry today. LEDs are solid-state semiconductor devices that directly convert electrical energy into light. Power, energy efficiency, maintenance savings, impact resistance and durability make LEDs suitable for safety signals for railway, road traffic and other applications in stationary transportation [1].

However, thermal management is still one of the major issues to be improved for implementing LEDs into lighting fixtures. In general, any electrical components generate heat whilst running; if these components are housed in a confined space, the internal temperature of enclosure can rise well above the ambient temperature, resulting degraded performance or burnout for the system. This is exacerbated if the enclosure is exposed to solar radiation. In fact, the reliability of electronic components is strongly influenced by the operating temperature. For the United States Air Force, more than 55\% of failures in electronics are caused by high temperature [2]. Therefore, a good thermal management system is required to maintain specifications and have a long lifetime. Furthermore, when

This paper is part of the proceedings of the 15th International Conference on Railway

Engineering Design and Operation (COMPRAIL)

www.witconferences.com 
the LEDs are used as light source in the railway signals, the optical proprieties of these have to maintain rigorous colour-intensity specifications on ample temperature range (typically -25 to $+70^{\circ} \mathrm{C}$ ). Again, one drawback with using LEDs in stationary transportation signal is that optical proprieties of LEDs degrade with increasing temperature. In other words, the intensity and the colorimetric coordinates of LED radiation depend on junction temperature [3]. In a typical railway signal, the heat generated inside the junction is dissipated into the ambient; changing the ambient temperature modifies the junction temperature and hence the characteristics of emitted light. The ambient temperature affects both the intensity and the colour of the radiation emitted by the LED systems; the intensity of the radiation decreases with higher ambient temperature and dominant wavelength increases. Therefore, in designing a signal system that makes use of LEDs, a good thermal management system is required to maintain a long lifetime and compliance. Hence, designing a LED railway signal that is able to meet compliance over wide range of temperatures is very problematic. In particular for yellow aspects, compliance is difficult to achieve at extreme ambient temperature because the shift in the colour of yellow LEDs over a specified temperature range can be greater than the magnitude of colour specification. Without a mechanism to compensate this phenomenon, unacceptable situations can occur on stationary transportation signals carried out with LEDs, especially when these signals are installed in climates where solar radiation can produce high temperatures inside their signal enclosure. To solve this problem, a number of conventional temperature compensation circuits have been designed which use sensors and opportune feedback techniques [4-9]. All of these systems work well. Unfortunately, they increase the complexity of the system. Consequently, with the same reliability and safety, we have higher production costs. The problem of incomplete conformity of the signals within a wide temperature range is very important. For this reason, the most important companies producing LED (e.g. NICHIA Corporation) have designed and manufactured LEDs for application in stationary transportation signals. These LEDs are devices made by combining blue LEDs and special phosphors. Consequently, it is possible to obtain LEDs with stable photometric characteristics [10]. However, while on one hand blue LED chips can have high reliability, on the other hand several reports have demonstrated that the phosphors can severely degrade during device lifetime. Mainly this is due to the high temperature levels reached in the proximity of the LED chips during operation [11-13]. For all these reasons, in this paper we propose a passive cooling that is able to accumulate energy during the day and release it during the night. In this way, we can minimize thermal excursions. In other words, we can eliminate the temperature peaks and get smaller thermal oscillation. The temperature fluctuations within a railway signal can be attenuated with adding thermal mass. Thermal mass acts as a passive energy store to attenuate temperature fluctuations inside signals [14]. In particular, adding phase change material (PCM) to thermal mass increases the effective heat capacity during the phase transition. This can anchor the temperature of the mass in a narrow band around the melting point of the PCM, reducing the temperature swings of the LEDs used in the signal. This paper presents the use of PCMs for thermal management solutions of railway signals. With use of the phase transition materials it is possible to design railway signals that are able to meet, in a rigorous way, colorimetric compliances on a large range of temperature. Furthermore, the proposed approach is applicable, in a simple way and without changes, on the signals in the existing systems. Simply insert a suitable quantity of specific PCM inside the railway light housings. The amount and the melting point of the PCM must be chosen in function of the environmental temperature variation. 


\section{OVERVIEW OF PCM}

PCMs are materials which undergo a change in physical phase when a sufficient amount of heat is supplied. An example is transition from solid into liquid (melting). During the time when the material actively melts, additional heat, applied to material, does not change the temperature of the same. This phenomenon continues until the entirety of material melts. A typical temperature profile of a PCM is shown in Fig. 1. Like it shows, if heat is added to a solid PCM below its melt temperature or a liquid PCM above its melt temperature, the energy is stored as sensible heat and increases the temperature of solid or liquid. When phase change occurs PCMs operate by storing energy at a constant temperature, like transition from solid to liquid as illustrated in the centre of Fig. 1. In particular, in this phase transition, heat added to the material does not rise the temperature, and indeed it drives the phase change of material to a higher energy phase. In fact, liquid phase has a kinetic energy of the motion of atoms that is not present in the solid, so its energy is higher than that. In particular, the energy difference between the liquid and solid state defines latent heat - heat used for phase transition. Of course, when the solid is fully transformed into liquid, adding energy reverts to going into sensible heat and raising the temperature of the liquid [15].

Therefore, as liquid freezes and returns to a solid, it releases energy (heat) to the surrounding environment, which is stored in the kinetic energy of the motion of atoms. When a PCM freezes, it releases a large amount of energy in the form of latent heat at a relatively constant temperature. Conversely, when such material melts, it absorbs a large amount of heat from the environment. The property of storing and releasing thermal energy during the process of melting and freezing (transition from one phase to another) makes PCMs the ideal products for thermal management solutions. Like physical mass, PCMs offer the potential to reduce fluctuations in temperature and shift cooling loads to off-peak periods. However, in contrast to physical mass, whose energy storage capability is restricted by sensible heat, the ability of a PCM to store energy is characterized by its latent heat of fusion. So if latent heat of fusion increases, the material's capacity to store heat also increases. PCMs can be used for a variety of everyday applications that require temperature control. To meet better the various types

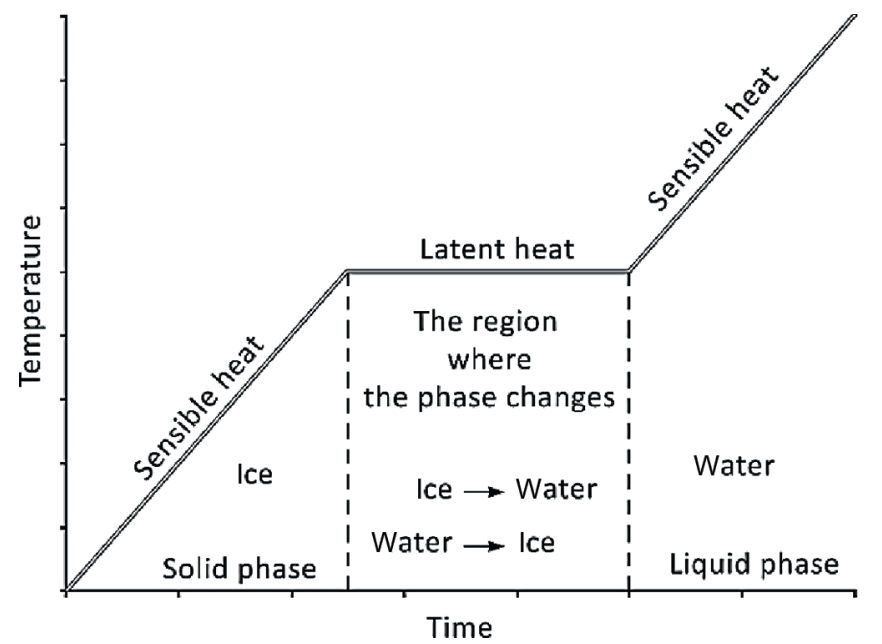

Figure 1: Temperature profile of a PCM. In the region where latent heat is effective, the temperature keeps either constant or in a narrow range. The phase of the material turns from one to another and both phases appear in the medium. 


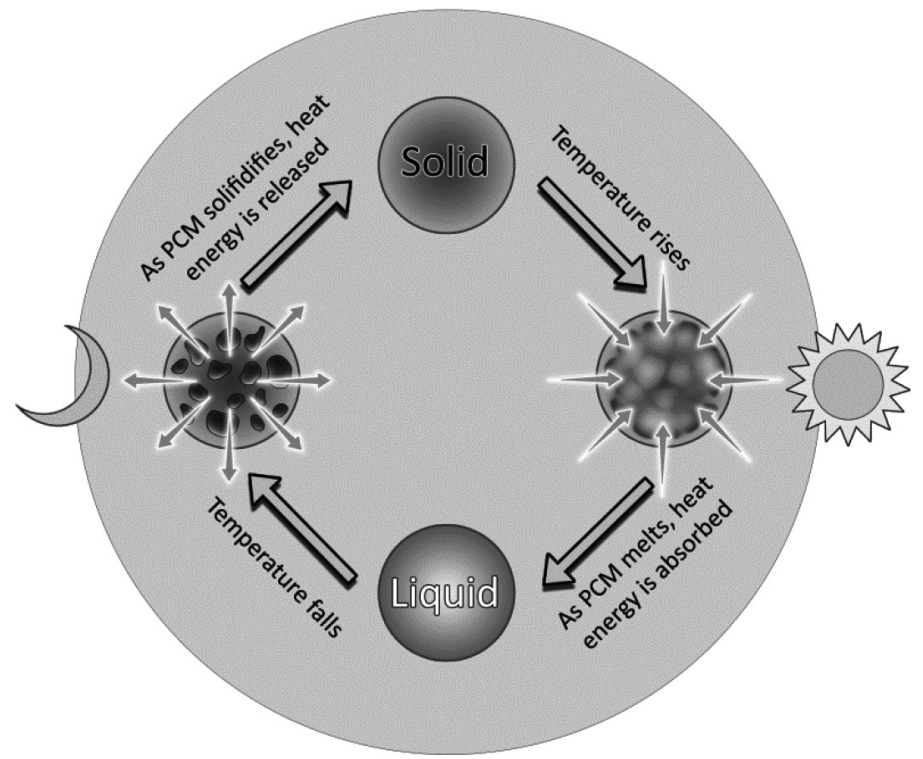

Figure 2: Description of how a PCM works.

of uses, like all materials that change phase at specific temperatures, PCMs are engineered to change phase at a temperature appropriate for their use and to store an unusual amount of thermal energy. PCMs are able to store 5-14 times more thermal energy per unit volume than conventional thermal storage materials. Figure 2 depicts schematically how PCM works. As a cycle, when temperature rises PCM melts and absorbs heat, and when temperature decreases PCM solidifies and provides a warming effect.

Heat is absorbed and released almost isothermally so that PCM reduces thermal peak loads. In fact, Fig. 3 shows the objective of PCM. As can be seen, PCM limits excessive temperatures by storing the excess heat during the day and releasing it during the night. This mode mimics the effect of thermal mass.

The use of PCMs has been proposed as a passive cooling technique of electronic systems [17-21]. Every electrical component generates heat during operation; if these components are housed in a confined space, the internal temperature of the housing can rise well above

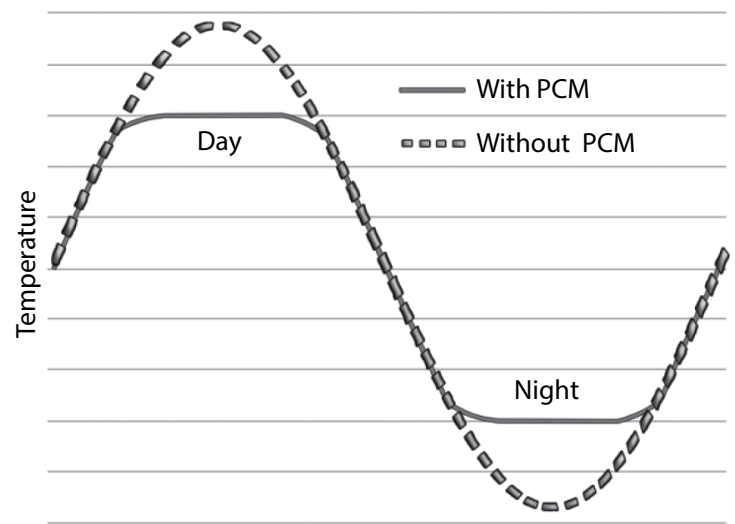

Figure 3: Objective of PCM; PCM limits excessive temperature variations. 
the ambient temperature, resulting degradation of the performance. This is exacerbated if the housing is exposed to the sun. So, in many case, use of PCMs is a better alternative than classic cooling techniques. In fact, PCM heat sinks have been recognized, by the NASA, as an important tool in optimizing thermal control systems for space exploration vehicles and habitats that must deal with widely varying thermal loads and environments. Naturally, it is difficult to get a PCM ideal for a particular application. Certain amount of trade-off between different properties is therefore essential. Selection of a suitable PCM, determination of its quantity requirements based on heat-balance calculations, packaging of PCM, design of heat exchanging and heat distribution surfaces are other important steps in developing an effective PCM-based device or product [22].

\section{SIGNAL CHARACTERIZATION: THERMAL EFFECT}

In general, a railway signal is consisted of a housing inside which the actual signal is inserted. The thermal performance of signal system depends on a large number of factors. A block diagram that shows various factors affecting the heat balance of a signal system is presented in Fig. 4. The influence of these factors on performance of a signal system can be studied using an appropriate heat transfer model.

In our study, for the total heat rate (enthalpy flow rate at constant pressure), we have considered $[23,24]$

$$
C \frac{\partial T}{\partial t}=A \cdot K \cdot \Delta T+Q_{\text {internal }}
$$

where

$K=$ global heat transfer coefficient associated to a transfer area $A$

$C=\sum_{j} m_{\mathrm{j}} \cdot c_{\mathrm{pj}}$, with $m_{\mathrm{i}}$ element mass and $c_{\mathrm{pi}}$ the corresponding specific heat (the subscript

$Q_{\text {internal }}=$ heat produced by the signal during its normal condition

$\Delta T=$ average temperature jump between the system and the surroundings.

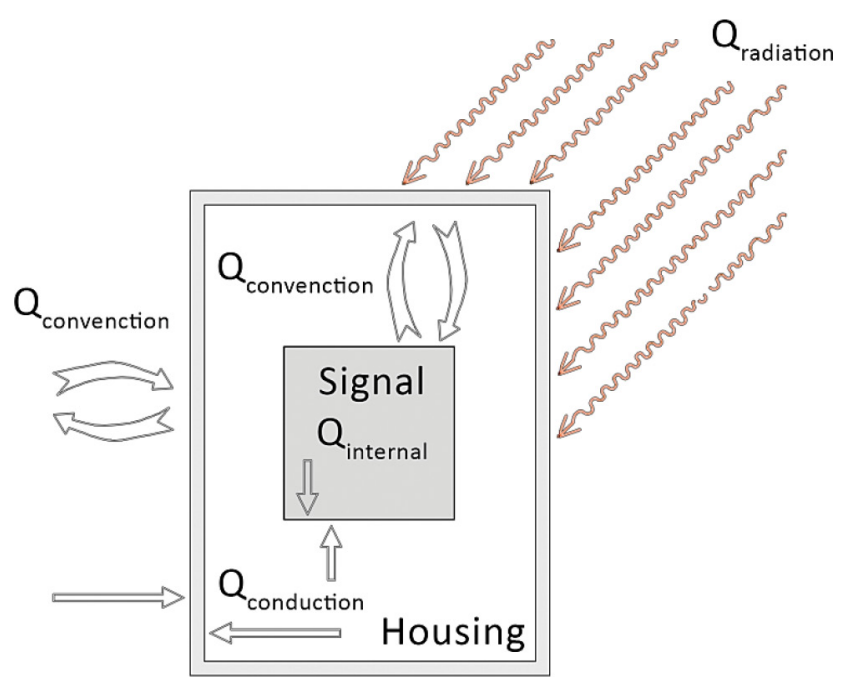

Figure 4: Heat exchange processes between a signal system and the external environment. 
If the surface is exposed (as it is normally done for signals positioned along the railway line), we can consider $\Delta T=T_{\text {so }}-T_{\mathrm{i}}$, where $T_{\mathrm{i}}$ is the signal housings temperature and $T_{\text {so }}$ is the sol-air temperature, calculated using the expression

$$
T_{\mathrm{so}}=T_{\mathrm{o}}+\frac{\alpha S_{\mathrm{T}}}{h_{\mathrm{o}}}-\frac{\varepsilon \Delta R}{h_{\mathrm{o}}},
$$

where

$T_{\mathrm{o}} \quad=$ daily average value of hourly ambient temperature

$\alpha=$ absorbance of the surface for solar radiation

$S_{\mathrm{T}}=$ daily average value of hourly solar radiation incident on the surface

$h_{\mathrm{o}} \quad=$ outside heat transfer coefficient

$\varepsilon \quad=$ emissivity of the signal housings surface

$\Delta R=$ difference between the long wavelength radiation incident on the housings surface from the sky and the surroundings, and the radiation emitted by a black body at ambient temperature.

Determining all parameters of interest is extremely difficult. For this reason, after a first estimate, the model was calibrated by experimental measurements. Therefore, in the signal system some temperature sensors were positioned. Furthermore, temperature, wind direction and speed, and solar radiation were measured outside the housing. Figure 5 shows experimental set-up used. With this experimental apparatus we measured the temperature variations inside the signal vs the variability of environmental conditions. These measurements have allowed us to fully characterize our heat rate model. Figure 6 shows an example of the measurements used to calibrate the model.

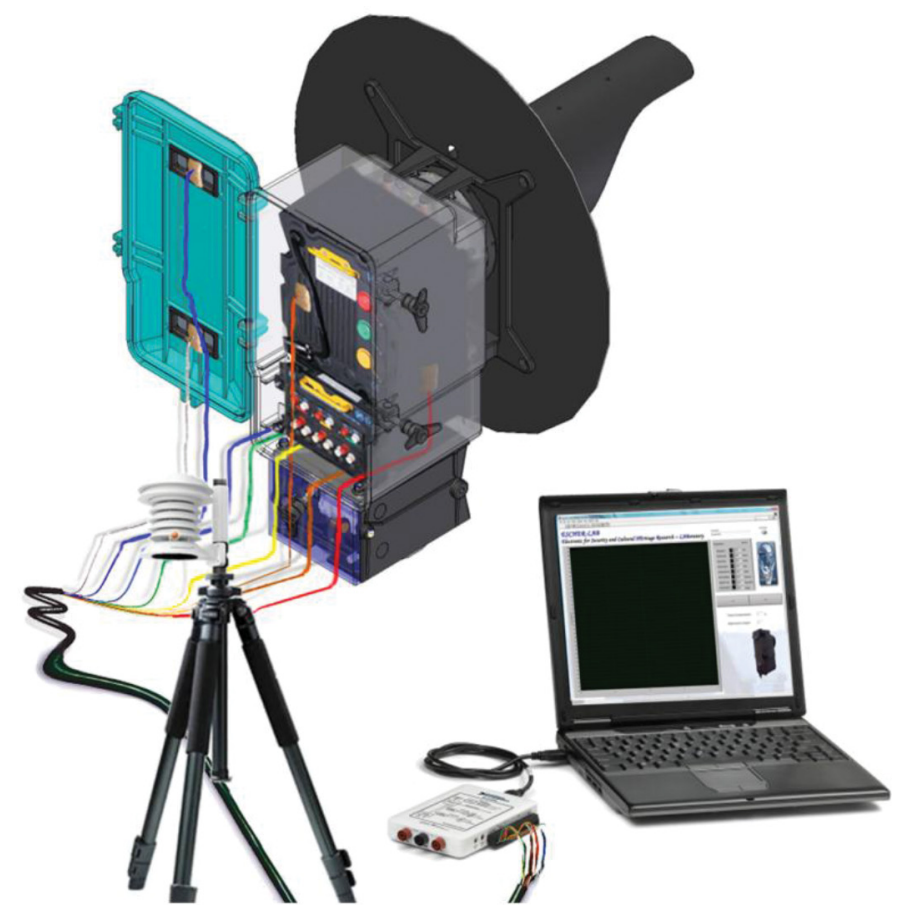

Figure 5: Experimental apparatus used to calibrate the total heat rate model. 


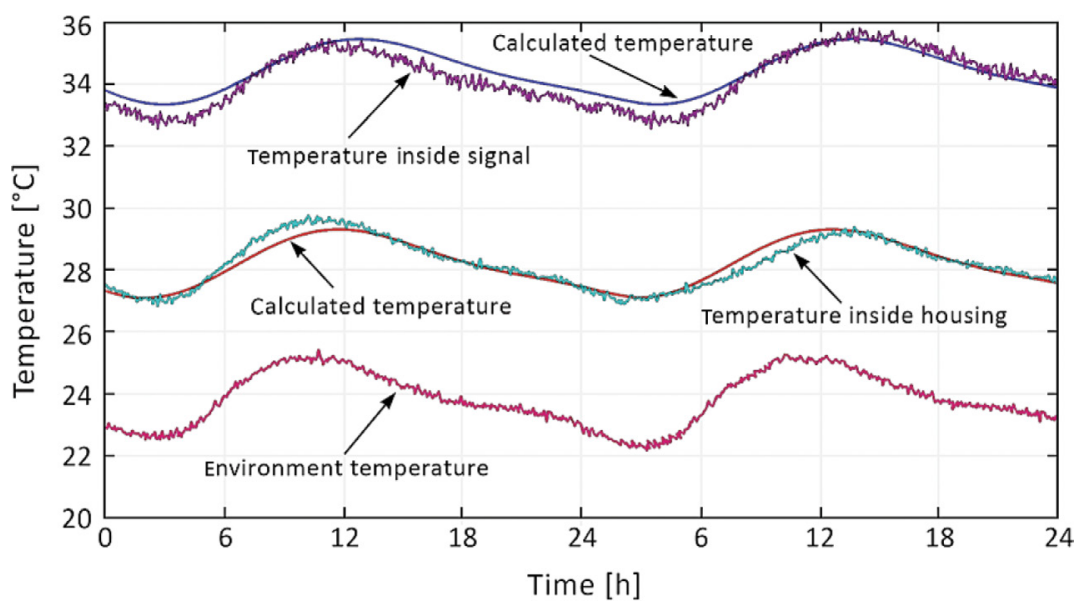

Figure 6: Example of measures made to calibrate the model.

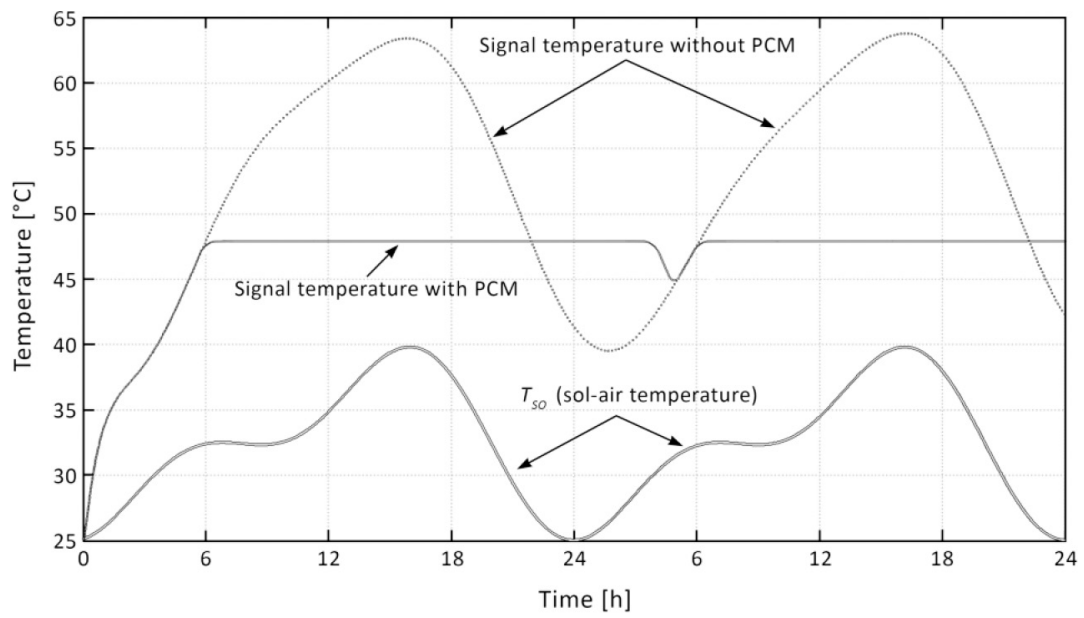

Figure 7: Numerical simulation showing the thermal behaviour of signal system with and without PCM. Looking at the figure is easy to see that the PCM reduces the temperature variation to which the signal is subjected.

Obtaining a realistic model for signal system, we can use this to predict the temperature trend in the case when a suitable amount of PCM is inserted inside the housing. In this case, the model becomes

$$
C \frac{\partial T}{\partial t}=A \cdot K \cdot \Delta T+Q_{\text {internal }},
$$

which is valid for temperatures below the melting temperature of the PCM:

$$
0=A \cdot K \cdot\left(T_{\text {melting-PCM }}-T_{\mathrm{i}}\right)+Q_{\text {internal }},
$$

in other cases, with the restriction that the PC is not completely melted. 
Therefore, we have hypothesized to place inside the housing $6 \mathrm{~kg}$ (about $8 \mathrm{dm}^{3}$ ) of PCMRT-50Rubitherm ${ }^{\circledR} \mathrm{GmbH}\left(\right.$ latentheat $168 \mathrm{~kJ} / \mathrm{kg}$ andmelting point $48^{\circ} \mathrm{C}$ ). Wealsoconsidered that the signal is subjected to a sol-air temperature variation between 25 and $40^{\circ} \mathrm{C}$. Finally, we made the assumption that every day, and at night, the PCM solidifies completely. Figure 7 shows the numerical simulation obtained with our model.

Figure 7 shows that the use of PCMs reduces the temperature range to which the signal is subjected. Reduced thermal excursions, in particular the high temperature, improve the performance of the LEDs and increase the reliability of the system. Obviously, the type and characteristics of the used PCM depend on the thermal characteristics of the signal and the average environmental conditions present in the installation area.

\section{CONCLUSIONS}

The objective of this paper has been to investigate the feasibility of using PCMs for application in thermal control of railway signals. In particular, we have shown that the use of the PCM can reduce the temperature fluctuations to which a rail signal is subjected. In particular, for yellow aspects compliance is difficult to achieve at extreme ambient temperature because the shift in the colour of yellow LEDs over the specified temperature range can be greater than the magnitude of colour specification. Use of PCMs can provide practical solution of these problems. In this paper, we introduced an innovative technical to allow the use of PCMs for thermal management solutions of railway signals. With the use of PCMs can be designed railway signals to maintain rigorous colour-intensity specifications on ample temperature range. Furthermore, since the use of the PCM decreases the likelihood that the equipment works at relatively high temperatures, the reliability and the lifetime of the signals increases. On the other hand, although the use of PCM has been proposed to improve the performance of railway signals, the same methodology can be used to improve reliability and decrease the probability of becoming out of order, for all those electronic systems subject to considerable temperature fluctuations. In fact PCM-based electronic cooling devices in aerospace and defence application are being used successfully by government agencies like NASA or defence industry. Unfortunately, these systems are unavailable off the shelf commercially and design information is a closely guarded trade secret. Anyway, successful systems with thermal management obtained by means of PCMs depend on thermal reliability and stability of PCM used. Many international companies like BASF, Climator, Cristopia, EPS Ltd., Mitsubishi Chemical Corporation, Rubitherm GmbH, TEAP, Witco., etc., are marketing PCMs, but it is still important to study PCMs for industrial applications and develop and test new materials.

\section{REFERENCES}

[1] Suozzo, N., Borg, D., Frering, M., Lucas, P. Vrabel, LED traffic lights: Signaling a global transformation. Proceedings American Council for an Energy Efficient Economy Summer Study on Energy Efficiency in Buildings (ACEEE), Panel 6: Market Transformation, pp. 6.391-6.402, 2000, available at http://www.eceee.org/library/conference_ proceedings/_buildings/2000/Panel_6/p6_34 (accessed 22 February 2016).

[2] Yeh, L., Review of heat transfer technologies in electronic equipment. Journal of Electronic Packaging, 117(4), pp. 333-339, 1995. DOI: 10.1115/1.2792113.

[3] Zheludev, N., The life and times of the LED - a 100-year history. Nature Photonics, 1(4), pp. 189-192, 2007. DOI: 10.1038/nphoton.2007.34.

[4] Grossman, H. \& Lambertville, N.J., LED driving circuitry with light intensity feedback to control output light intensity of an LED. United States Patent n. 6,153,985, 28 
November 2000, available at https://www.google.com/patents/US6153985 (accessed 22 February 2016).

[5] Wu, C.H. \& Chuang, H.J., LED power supply with temperature compensation, United States Patent n. 6,111,739, 29 August 2000, available at https://www.google.com/ patents/US6111739 (accessed 22 February 2016).

[6] Schirripa Spagnolo, G., Papalillo, D. \& Martocchia, A., LED applications in railway signals: wavelength and intensity vs temperature variation. Journal of Transportation Technologies, 2, pp. 78-83, 2012. DOI: 10.4236/jtts.2012.21010

[7] Papalillo, D., Del Vecchio, P. \& Schirripa Spagnolo, G., LED applications in road and railway signals: is it possible to fit specifications? Proc. SPIE 8306, Photonics, Devices, and Systems $V, 83061 \mathrm{~N}, 11$ October 2011. DOI: 10.1117/12.912384.

[8] Schirripa Spagnolo, G., Papalillo, D. \& Martocchia, A., Light emitting diode in stationary transportation applications: wavelength response to varying temperature. Proceedings SPIE 8278, Light-Emitting Diodes: Materials, Devices, and Applications for Solid State Lighting XVI, 82781P, 9 February 2012. DOI: 10.1117/12.909490.

[9] Schirripa Spagnolo, G., Papalillo, D., Martocchia, A. \& Makary, G., Application of LEDs to traffic signal, Environment and Electrical, 11th International Conference on Engineering (EEEIC), pp. 864-868 (Venice, Italy, 18-25 May 2012. DOI: 10.1109/ EEEIC.2012.6221497.

[10] Mills, A., Phosphors development for LED lighting. III-Vs Review, 18(3), pp. 32-34, 2005. DOI: 10.1016/S0961-1290(05)01052-5.

[11] Meneghini, M., Trevisanello, L.R., Meneghesso, G. \& Zanoni, E., A review on the reliability of Gan-based LEDs. IEEE Transactions on Device and Materials Reliability, 8(2), pp. 323-331, 2008. DOI: 10.1109/TDMR.2008.921527.

[12] Meneghesso, G., Meneghini, M. \& Zanoni, E., Recent results on the degradation of white LEDs for lighting, 19 August 2010. Journal of Physics D: Applied Physics, 43(35), p. 354007, 2010. DOI: 10.1088/0022-3727/43/35/354007.

[13] Meneghini, M., Dal Lago, M., Trivellin, N. \& Meneghesso, G., Thermally activated degradation of remote phosphors for application in LED lighting, IEEE Transactions on Device and Materials Reliability, 13(1), pp. 316-318, 2013. DOI: 10.1109/ TDMR.2012.2214780.

[14] Richardson, M.J. \& Woods, A.W., An analysis of phase change material as thermal mass. Proceedings of the Royal Society A, pp. 1029-1056, 2008. DOI: 10.1098/ rspa.2007.0312.

[15] Al-Hallaj, S. \& Kizilel, R., Applications of phase change materials for sustainable energy, OpenStax-CNX module: $\mathrm{m} 41734$, version 1.4, Mar 1, 2012, available at http:// cnx.org/content/m41734/1.4/ (accessed 22 February 2016).

[16] Hale, D.V., Hoover, M.J. \& O’Neill, M.J., Phase change materials handbook. NASA CR-61363, Marshal Space Flight Centre. Alabama. 1971, available at http://ntrs.nasa. gov/archive/nasa/casi.ntrs.nasa.gov/19720012306.pdf (accessed 22 February 2016).

[17] Kumar, R., Misra, K.M., Kumar, R., Gupta, D., Sharma, P.K., Tak, B.B. \& Meena, S.R., Phase change materials: technology status and potential defence applications. Defence Science Journal, 61(6), pp. 576-582, 2011. DOI: 10.14429/dsj.61.363.

[18] Kandasamy, R. \& Wang, X.Q., Application of phase change materials in thermal management of electronics. Applied Thermal Engineering, 27(17-18), pp. 2822-2832, 2007. DOI: 10.1016/j.applthermaleng.2006.12.013. 
[19] Pal, D. \& Joshi, Y.K., Melting in a side heated tall enclosure by a uniformly dissipating heat source. International Journal of Heat and Mass Transfer, 44, pp. 375-387, 2001. DOI: 10.1016/S0017-9310(00)00116-2.

[20] Tan, F.L. \& Tso, C.P., Cooling of mobile electronic devices using phase change materials. Applied Thermal Engineering, 24, pp. 159-169, 2004. DOI: http://dx.doi. org/10.1016/j.applthermaleng.2003.09.005

[21] Lu T.J., Thermal management of high power electronics with phase change cooling. International Journal of Heat and Mass Transfer, 43(13) pp. 2245-2256, 2000. DOI: 10.1016/S0017-9310(99)00318-X.

[22] Mehling, H., \& Cabeza, L.F., Heat and Cold Storage with PCM. Hand Book, Springer: Berlin, Germany, 2008. ISBN: 978-3540685562

[23] Kreith, F., Manglik, R.M. \& Bohn, M.S., Principles of Heat Transfer, 7th ed., CL Engineering: Stamford, CT, 2010. ISBN-13: 978-0495667704.

[24] Dutila, Y., Roussea, D.R., Salahb, N.B., Lassuec, S. \& Zalewskic, L., A review on phasechange materials: Mathematical modeling and simulations, Renewable and Sustainable Energy Reviews, 15(1), pp. 112-130, 2011 DOI: 10.1016/j.rser.2010.06.011. 